\title{
COMPARISON OF INTRACORONARY VERAPAMIL VS ADENOSINE FOR RESTORATION OF CORONARY BLOOD FLOW POST PERCUTANEOUS CORONARY INTERVENTION (PCI) IN PATIENTS WITH NO-REFLOW
}

\author{
Mohsin Saif, Obaid-Ur-Rahman, Muhammad Umar Amin, Hamid Sharif Khan, Ghulam Rasool Maken, Qamar-Uz-Zaman \\ Bhatti, Zohair Aziz, Anam Fatima Janjua, Sohail Aziz \\ Armed Forces Institute of Cardiology/National Institute of Heart Disease (AFIC/NIHD)/National University of Medical Sciences (NUMS) \\ Rawalpindi Pakistan
}

\begin{abstract}
Objective: To determine the efficacy of intracoronary verapamil vs adenosine in restoration of coronary blood flow, post PCI in patients with No-Reflow.

Study Design: Double blind (patient/operator blind) randomized control trial.

Place and Duration of Study: Cath lab of AFIC \& NIHD Rawalpindi, from Feb 2019 to Aug 2019.

Methodology: A total of ninety $(n=90)$ patients of either gender between age 25-80 years of age who underwent angioplasty for STEMI/NSTEMI demonstrating No-Reflow (thrombolysis in myocardial infarction 0,1,2) post PCI were enrolled and were randomized into two groups. Group A received verapamil $500 \mu \mathrm{g}$ in $10 \mathrm{ml}$ heparinized saline, given slowly over 1 minute and group B received adenosine $60 \mu \mathrm{g}$ in $10 \mathrm{ml}$ of heparinized saline, given quickly. After the administration of both drugs repeat angiogram was carried out and thrombolysis in Myocardial Infarction flow was assessed. Restoration of blood flow was defined as achievement of thrombolysis in myocardial infarction 3 grade.

Results: Efficacy (restoration of thrombolysis in Myocardial Infarction grade 3) was better with intracoronary administration of verapamil when compared with intracoronary administration 2 of adenosine ( $84.4 \%$ vs $80 \%)$. The difference was, however, not statistically significant $(p=0.581)$.

Conclusion: Efficacy (restoration of thrombolysis in myocardial infarction grade 3) was not statistically significant between intracoronary administration of verapamil and adenosine in no-reflow cases after PCI in patients with STEMI/NSTEMI.
\end{abstract}

Keywords: No-reflow, NSTEMI, PCI, STEMI, Thrombolysis in Myocardial Infarction flow.

This is an Open Access article distributed under the terms of the Creative Commons Attribution License (http://creativecommons.org/licenses/by/4.0), which permits unrestricted use, distribution, and reproduction in any medium, provided the original work is properly cited.

\section{INTRODUCTION}

Myocardial infarction is one of the leading causes of morbidity, mortality and first choice of treatment is Primary Percutaneous Coronary Intervention to restore blood flow in infarct related artery (IRA).

No-reflow is the term used to describe inadequate myocardial reperfusion of a given coronary segment without evidence of epicardial vessel obstruction or apparent in situ thrombosis $^{1}$. Persistent no re-flow significantly increases the risk of poor outcomes including death, MI and left ventricular systolic dysfunction ${ }^{2}$. The pathophysiology of no-reflow involving microva-

Correspondence: Dr Mohsin Saif, Consultant Cardiologist, AFIC/NIHD, Rawalpindi Pakistan sculature is multifactorial such as micro vascular spasm, micro-embolization, neutrophil plugging, high endothelial oxidative stress, and endothelial blistering and tissue edema. Ischemia-reperfusion has a central role in pathology of No-reflow ${ }^{3}$.

Intracoronary administration of adenosine as an adjunct to reperfusion can improve outcomes by causing vasodilation 4 . Verapamil a calcium channel blocker has effect on coronary circulation and platelet aggregation. It not only relieves microcirculation spasm by reducing calcium influx but also relieves cellular edema and restores calcium hemostasis. These additional features put verapamil ahead of other drugs ${ }^{5-8}$.

The time to onset of reperfusion therapy is a critical determinant of outcome with both PPCI and fibrinolysis9. 
The total time between the onset of symptoms and primary percutaneous coronary intervention (PPCI), is termed the treatment delay ${ }^{10}$.

With regards to fibrinolytic therapy, the benefit (myocardial salvage and functional improvement) is greatest when fibrinolytics are given within the first two to three hours after the onset of symptoms, particularly within the first 70 minutes ${ }^{11,12}$.

In different registries of patients, the time from symptom onset to hospital presentation was $\geq 4$ hours in 50 percent (a value that changed little from 1987 to 2000) ${ }^{13}$, more than six hours in $40 \% 14$, and more than 12 hours in $9-31 \% 15,16$. Data from an observational study found a lower percentage of late presenters $(32 \%)$ in patients undergoing primary percutaneous coronary intervention (PPCI). Delay is greatest in women, older adults, low socioeconomic and ethnic minority groups, and in those with symptoms that occur between $6 \mathrm{PM}$ and $6 \mathrm{AM}^{17}$. Initial studies primarily evaluated outcomes with percutaneous transluminal coronary angioplasty (PTCA) without stenting, which is no longer the standard procedure. The data were conflicting as to whether there is ${ }^{18-21}$ or is $\operatorname{not}^{22,23}$ a significant relationship between mortality and the time from symptom onset to reperfusion similar to that seen with fibrinolytic therapy with PTCA.

\section{METHODOLOGY}

Double blind (patient/operator blind) randomized control trial. Study was conducted at Cath lab of AFIC \& NIHD Rawalpindi Duration: 6 months, from 11 th feb 2019 to $10^{\text {th }}$ Aug 2019. Sample size was calculated using OPEN EPI with $5 \%$ level of significance and $80 \%$ power. Two sided confidence level $=95 \%$ Power $(1$-beta) $=$ $80 \%$ Ratio of unexposed to exposed in sample $=$ $1 \%$ of unexposed with outcome $=38$ Percent of exposed with outcome $=11.87$ Risk ratio $[R R]=$ 0.33 Sample size $=90$ (study participants in each group 45). Non probability consecutive sampling.

Inclusion Patients diagnosed as STEMI/ NSTEMI undergoing angioplasty either primary or elective and having No-Reflow post PCI. Age: 25-80 years, Both genders

Patients with asthma, renal impairment (creatinine more than $1.4 \mathrm{mg} / \mathrm{dl}$ ), left main stem disease, blood pressure less than $90 \mathrm{mmHg}$, known heart block were excluded.

This double-blind randomized control trial was carried on all STEMI / NESTMI patients undergoing PCI and having No-Reflow. Permission was sought from hospital ethics committee. Written informed consent from the participants undergoing PCI was taken. PCI of the culprit artery was carried out and after completion of angioplasty, coronary angiogram in appropriate views taken and TIMI flow assessed after PCI. Patient with no distal flow in 57 coronaries termed as No-Reflow include TIMI 0 to 2 and were subjected to drug treatment. Post PCI patients were randomly assigned to receive an intracoronary bolus of the study drugs. Group A (45 participants) received verapamil $500 \mu \mathrm{g}$ in $10 \mathrm{ml}$ heparinized saline, given slowly over 1 minute and repeat angiogram recorded after 1 minute. Group B (45 participants) received adenosine $60 \mu \mathrm{g}$ in $10 \mathrm{ml}$ of heparinized saline, given quickly and repeat angiogram recorded within 10 seconds. After the administration of both drugs TIMI flow was assessed. Reflow parameter i.e. Restoration of blood flow was achievement of TIMI 3 grade. In case of multi vessel PCI, the study drug was given once only to one of the vessels and repeat angiogram was assessed after drug administration. All patients received aspirin, clopidogrel and unfractionated heparin before PCI.

For non-emergency procedures clopidogrel was given 2 to 4 days before the patients were taken to catheterization laboratory.

Statistical analysis was performed using statistical software SPSS version 23. Frequency and percentage were calculated for qualitative variable i.e. gender, efficacy of drug (reflow achieved i.e. TIMI 3). Means \pm standard deviation was calculated for age, duration of diabetes, hypertension and smoking pack year. Effect modifiers like age, gender, diabetes, hypertension 
and smoking duration were controlled by stratification. Post stratification chi 58 square was applied. Efficacy was compared between groups by Chi square test. A $p$-values less than 0.05 $(p<0.05)$ was significant.

\section{RESULTS}

A total of ninety $(n=90)$ patients of either gender between age 25-80 years of age who underwent angioplasty for STEMI/NSTEMI demonstrating No-Reflow (TIMI 0,1,2) post PCI were enrolled and were randomized into two groups. Group A received verapamil $500 \mu \mathrm{g}$ in $10 \mathrm{ml}$ heparinized saline, given slowly over 1 minute and group B received adenosine $60 \mu \mathrm{g}$ in $10 \mathrm{ml}$ of heparinized saline, given quickly. After the administration of both drugs repeat angiogram was carried out and TIMI flow was asse-

Table-I: Patient's characteristics $(\mathrm{n}=90)$.

\begin{tabular}{l|c|c}
\hline \multirow{2}{*}{ Variables } & \multicolumn{2}{|c}{ Groups } \\
\cline { 2 - 3 } & Verapamil & Adenosine \\
\hline Age (years) & $50.7 \pm 9.7$ & $52.6 \pm 8.7$ \\
\hline Gender & $23(51.1 \%)$ & $33(73.3 \%)$ \\
Male & $22(48.9 \%)$ & $12(26.7 \%)$ \\
Female & $4.1 \pm 4.1$ & $6.3 \pm 5.7$ \\
\hline Hypertension & $5.2 \pm 4.9$ & $5.5 \pm 5.1$ \\
\hline Diabetes & $4.3 \pm 4.3$ & $2.9 \pm 5.1$ \\
\hline Smoking &
\end{tabular}

Table-II: Efficacy of treatment in both groups.

\begin{tabular}{l|c|c|c}
\hline \multirow{2}{*}{ Efficacy } & \multicolumn{2}{|c|}{ Groups } & \multirow{2}{*}{-value } \\
\cline { 2 - 3 } & Verapamil & Adenosine & \\
\hline Present & $38(84.4 \%)$ & $36(80.0 \%)$ & \multirow{2}{*}{0.581} \\
\hline Absent & $7(15.6 \%)$ & $9(20.0 \%)$ & \\
\hline
\end{tabular}

ssed. Restoration of blood flow was defined as achievement of TIMI 3 grade. Mean age (years), duration (years) of hypertension, diabetes, hyperlipidemia and smoking is presented in table-I.

Efficacy (restoration of TIMI grade 3) was better with intracoronary administration of verapamil when compared with intracoronary administration of adenosine ( $84.4 \%$ vs $80 \%)$. The difference was, however, not statistically significant $(p=0.581$, table-II).

No significant difference was noted in efficacy of treatment in both the groups when data was further stratified for gender, age, 60 duration of HTN, duration of diabetes, and duration of smoking. A $p$-value was $>0.05$ in all cases.

\section{DISCUSSION}

After successful percutaneous coronary intervention in patients with STEMI/NSTEMI, adequate myocardial reperfusion is not achieved in up to $50 \%$ of patients. This phenomenon of noreflow is associated with a poor in hospital and long-term prognosis.

Our results showed efficacy (restoration of TIMI grade 3) was better with intracoronary administration of verapamil when compared with intracoronary administration of adenosine $(84.4 \%$ vs $80 \%)$. The difference was, however, not statistically significant $(p=0.581)$.

To the best of our knowledge, there is only one trial found in the literature that compares intracoronary administration of adenosine and verapamil for the treatment of no-reflow phenomenon after PCI. Akturk et al aimed to investigate the effects of verapamil and adenosine in an adjunct to intravenous tirofiban on management and prognosis of no-reflow phenomenon during primary percutaneous coronary intervention (PPCI) and to compare their efficacies on reversing of no-reflow phenomenon and short and midterm survival.

Their results demonstrated that intracoronary verapamil therapy had significant effect in restoring impaired coronary blood flow by decreasing thrombolysis in myocardial infarction (TIMI) frame count from $73 \pm 44$ to $52 \pm 48(p=$ $0.024)$. However, adenosine and serum physiologic administration were not found to be so effective in decreasing TIMI frame count (from 81 \pm 35 to $71 \pm 46, p=0.084$; from $74 \pm 32$ to $7171 \pm 37$, $p=0.612$, respectively). In-hospital and 6-month survival rates were similar among groups. Authors concluded that intracoronary verapamil restored the impaired coronary blood flow more effectively than adenosine or placebo. However, none of them has changed the clinical course in the first 6 months ${ }^{12,2}$. The results are comparable with present study results (efficacy was better with intracoronary administration of verapamil 
when compared with intracoronary administration of adenosine ( $84.4 \%$ vs 80$)$.

Naing et al aimed to study the impact of adenosine and verapamil on people with AMI who were undergoing PPCI. They selected randomized controlled trials (RCTs) where adenosine or verapamil was the primary intervention. Participants were individuals diagnosed with AMI who were undergoing PPCI. They finally included 10 RCTs involving 939 participants in their review. Nine RCTs were associated with adenosine and one with verapamil. They demonstrated that both the drugs were efficacious in restoring coronary flow, however, no one drug was better than the other.

In summary, present study results and several other studies in the literature suggest that both adenosine and verapamil when administered as intracoronary agents are effective in treating no-reflow phenomenon after PCI. No one drug was found superior to the other. Several other drugs have also been used. We did not consider LVEF, mortality and reinfarction as the outcome variables. We suggest future studies in this regard.

\section{CONCLUSION}

Efficacy (restoration of TIMI grade 3) was not statistically significant between intracoronary administration of verapamil and adenosine in noreflow cases after PCI in patients with STEMI/ NSTEMI. We suggest further studies with larger sample size considering other parameters like LVEF, mortality and reinfarction rate.

\section{CONFLICT OF INTEREST}

This study has no conflict of interest to be declared by any author.

\section{REFERENCES}

1. Galasso G, Schiekofer S, Danna C, Gioia GD, Piccolo R, Niglio $\mathrm{T}$, et al. No-reflow phenomenon: pathophysiology, diagnosis, prevention, and treatment. A review of the current literature and future perspectives. Angiology 2014; 65(3): 180-9.

2. Rezkalla SH, Stankowski RV, Hanna J, Kloner RA. Management of no-reflow phenomenon in the catheterization laboratory. J Am Coll Cardiol Intv 2017; 10: 215-23.

3. Gupta S, Gupta MM. No reflow phenomenon in percutaneous coronary interventions in ST-segment elevation myocardial infarction. Indian Heart J 2016; 68(4): 539-51.
4. Bulluck H, Sirker A, Loke YK, Garcia-Dorado D, Hausenloy DJ. Clinical benefit of adenosine as an adjunct to reperfusion in STelevation myocardial infarction patients: An updated metaanalysis of randomized controlled trials. Intern J Cardiol 2016; 202(1): 228-37.

5. Su Q, Li L, Liu Y. Short-term effect of verapamil on coronary noreflow associated with percutaneous coronary intervention in patients with acute coronary syndrome: a systematic review and meta analysis of randomized controlled trials. Clinical Cardiol 2013; 36(8): e11-16.

6. Angiologica M. Effects of verapamil and adenosine in an adjunct to tirofiban on resolution and prognosis of noreflow phenomenon in patients with acute myocardial infarction. Minerva Cardioangiol 2014; 1(1): 1-5.

7. Su Q, Nyi TS, Li L. Adenosine and verapamil for no reflow during primary percutaneous coronary intervention in people with acute myocardial infarction. Cochrane Database Syst 2015; 1(5): CD009503.

8. Wang L, Cheng Z, Gu Y, Peng D. Short-term effects of verapamil and diltiazem in the treatment of no reflow phenomenon: a meta-analysis of randomized controlled trials. Bio Med Res Int 2015; 2015: 38208678.

9. Lambert L, Brown K, Segal E. Association between timeliness of reperfusion therapy and clinical outcomes in ST-elevation myocardial infarction. J Am Med Assoc 2010; 303: 2148-49.

10. Terkelsen CJ, Sørensen JT, Maeng M. System delay and mortality among patients with STEMI treated with primary percutaneous coronary intervention. J Am Med Assoc 2010; 304(1): 763-64.

11. Boersma E, Maas AC, Deckers JW, Simoons ML. Early thrombolytic treatment in acute myocardial infarction: reappraisal of the golden hour. Lancet 1996; 348(1): 771-72.

12. Indications for fibrinolytic therapy in suspected acute myocardial infarction: collaborative overview of early mortality and major morbidity results from all randomised trials of more than 1000 patients. Fibrinolytic Therapy Trialists' (FTT) Collaborative Group. Lancet 1994; 343(1): 311-14.

13. Mc Ginn AP, Rosamond WD, Goff DC. Trends in prehospital delay time and use of emergency medical services for acute myocardial infarction: experience in 4 US communities from 1987-2000. Am Heart J 2005; 150(1): 392-93.

14. Gurwitz JH, McLaughlin TJ, Willison DJ. Delayed hospital presentation in patients who have had acute myocardial infarction. Ann Intern Med 1997; 126(1): 593-94.

15. Eagle KA, Goodman SG, Avezum A. Practice variation and missed opportunities for reperfusion in ST-segment-elevation myocardial infarction: findings from the Global Registry of Acute Coronary Events (GRACE). Lancet 2002; 359(1): 373-75.

16. Grzybowski M, Clements EA, Parsons L. Mortality benefit of immediate revascularization of acute ST-segment elevation myocardial infarction in patients with contraindications to thrombolytic therapy: a propensity analysis. J Am Med Assoc 2003; 290: 1891-92.

17. Goff DC, Feldman HA, McGovern PG. Prehospital delay in patients hospitalized with heart attack symptoms in the United States: the REACT trial. Rapid Early Action for Coronary Treatment (REACT) Study Group. Am Heart J 1999; 138(1): 1046-47.

18. Brodie BR, Stuckey TD, Wall TC. Importance of time to reperfusion for 30-day and late survival and recovery of left ventricular function after primary angioplasty for acute myocardial infarction. J Am Coll Cardiol 1998; 32(1): 1312-13.

19. De Luca G, Suryapranata H, Zijlstra F. Symptom-onset-toballoon time and mortality in patients with acute myocardial 
infarction treated by primary angioplasty. J Am Coll Cardiol 2003; 42(1): 991-92.

20. De Luca G, Suryapranata H, Ottervanger JP, Antman EM. Time delay to treatment and mortality in primary angioplasty for acute myocardial infarction: every minute of delay counts. Circulation 2004; 109(1): 1223-24.

21. Tarantini G, Cacciavillani L, Corbetti F. Duration of ischemia is a major determinant of transmurality and severe microvascular obstruction after primary angioplasty: a study performed with contrast-enhanced magnetic resonance. J Am Coll Cardiol 2005;
46(7): 1229-33.

22. Cannon CP, Gibson CM, Lambrew CT. Relationship of symptom-onset-to-balloon time and door-to-balloon time with mortality in patients undergoing angioplasty for acute myocardial infarction. J Am Med Assoc 2000; 283(22): 2941-42.

23. Brodie BR, Stone GW, Morice MC. Importance of time to reperfusion on outcomes with primary coronary angioplasty for acute myocardial infarction (results from the Stent Primary Angioplasty in Myocardial Infarction Trial). Am J Cardiol 2001; 88(10): 1085-90. 